\title{
国国pubvet
}

https://doi.org/10.31533/pubvet.v14n7a606.1-5

\section{Avaliação ultrassonográfica em felino diagnosticado com pseudocistos perinéfricos: relato de caso}

\author{
Andreza Bernardi da Silva ${ }^{1 *}$, Carina Burkert da Silva ${ }^{2}$, Flávia Rocha da Silva ${ }^{3}$, Peter \\ Wachholz de $\operatorname{Lima}^{4} \bullet$
}

${ }^{I}$ Graduanda na Universidade Federal de Pelotas (UFPel). Departamento de Veterinária. Pelotas-RS, Brasil.

${ }^{2}$ Médica Veterinária graduada pela UFPel. Departamento de Veterinária. Pelotas-RS, Brasil.

${ }^{3}$ Médica Veterinária graduada pela Universidade de Vila Velha. Departamento de Veterinária. Vila Velha-ES, Brasil

${ }^{4}$ Médico Veterinário graduado pela Universidade da Região da Campanha. Departamento de Veterinária. Bagé-RS, Brasil.

*Autor para correspondência, E-mail: bernardiandreza@gmail.com

Resumo. Os pseudocistos perinéfrico são uma situação relativamente rara em gatos, tendose como um acúmulo de fluido entre o rim e sua cápsula, não havendo proteção pela camada de um epitélio, ainda que a natureza mais comum desse conteúdo seja liquido transudato. O diagnóstico presuntivo pode ser realizado por exames de imagem, dentre estes, principalmente a utilização de ultrassonografia abdominal. O objetivo deste trabalho foi relatar a avaliação ultrassonográfica de pseudocisto perinéfrico em um felino.

Palavras chave: diagnóstico por imagem, gato, nefrologia, pseudocisto perinéfrico, ultrassom

\section{Ultrasound evaluation in feline diagnosed with perinephric pseudocysts: case report}

\begin{abstract}
Perinephric pseudocysts are a relatively rare situation in cats. They are fluid accumulation between the kidney and its capsule, there is no protection by the layer of an epithelium, although the most common nature of this content is transudate fluid. The presumptive diagnosis can be made by imaging exams, among them, mainly the use of abdominal ultrasound. The aim of this paper was to report the sonographic evaluation of perinephric pseudocyst in a feline.
\end{abstract}

Keywords: diagnostic imaging, cat, nephrology, perinephric pseudocyst, ultrasound

\section{Evaluación ecográfica en felino diagnosticado con seudoquistes perirnefricos: reporte de caso}

Resumen. Los seudoquistes perinefricos son una situación relativamente rara en los gatos, es una acumulación de líquido entre el riñón y su cápsula, no hay protección por la capa de un epitelio, aunque la naturaleza más común de este contenido es el líquido transudado. El diagnóstico presuntivo puede hacerse mediante exámenes de imagen, entre ellos, principalmente el uso de ultrasonido abdominal. El objetivo de este trabajo fue informar la evaluación ecográfica de seudoquiste perinefrico en un felino.

Palabras clave: Diagnóstico por imágenes, gato, nefrología, seudoquiste perinéfrico, ultrasonido

\section{Introdução}

Os pseudocistos peri-renais (PPR) também conhecidos por pseudocistos perinéfricos, cistos renais capsulares ou capsulogênicos, hidronefrose capsular, ou pseudohidronefrose são acúmulos de conteúdo fluído que podem ser uni ou bilateral, localizados perirrenalmente, contido este por uma cápsula sem 
epitélio na face interior (Norsworthy et al., 2004). A natureza do conteúdo do cisto pode variar, sendo o achado mais comum o liquido transudato de baixo conteúdo proteico, densidade baixa e baixa celularidade. Já a cápsula do pseudocisto pode formar-se devido a uma reação inflamatória localizada, característica que os diferencia dos cistos renais verdadeiros que apresentam epitélio na face interior da cápsula (Ferreira, 2008).

A etiologia desta afecção pode ser causada pelo acúmulo de transudato decorrente de aumento da pressão hidrostática, obstrução linfática ou ruptura de cisto renal, o acúmulo de fluido hemorrágico pode ocorrer por coagulopatias, tumores, trauma e acidentes vasculares, enquanto que o acúmulo de urina pode ser proveniente de ruptura da pelve renal ou ureter, defeitos congênitos do trato urinário ou processo obstrutivo (Luís et al., 2003).

A prevalência está associada a felinos machos com mais de 8 anos de idade. Embora não se considere predisposição racial, já foi relatado em gatos persas, siameses, gatos domésticos de pelo curto e pelo longo (Mamprim \& Silva, 2012). A ocorrência do pseudocisto perinéfrico frequentemente está associada a doença renal crônica, cerca de $90 \%$ dos animais apresentam algum grau de comprometimento renal no momento do diagnóstico, por tanto muitos sinais clínicos estão relacionados à insuficiência renal, como são poliúria, polidipsia, anorexia, perda de peso e vômito. Ainda, os animais podem apresentar distensão abdominal indolor durante semanas ou até meses (Norsworthy et al., 2004).

Diferentes métodos de diagnóstico por imagem, como radiografia, ultrassonografia, urografia excretora, e menos utilizada a cintilografia e angiografia renal, podem ser utilizados na determinação desta enfermidade (Raffan et al., 2008). O exame ultrassonográfico é um método não invasivo, permitindo a visualização da presença de um fluido anecóico entre o parênquima e a cápsula renal e, por sua vez, excluindo outras causas de renomegalia. Ainda, serve de auxiliar no diagnóstico de doença renal pré-existente, sendo assim, considerado o exame de eleição para o diagnóstico dos pseudocistos perinéfricos (Beck et al., 2000; Luís et al., 2003).

O objetivo deste trabalho foi relatar a avaliação ultrassonográfica de pseudocisto perinéfrico em um felino macho de 3 anos de idade.

\section{Relato do caso clínico}

Foi atendido um gato macho, castrado, sem raça definida, de três anos de idade, pesando $5,5 \mathrm{~kg}$, com a queixa de anúria e constipação há dois dias. $\mathrm{O}$ felino não havia sido testado para retroviroses felinas; porém, vacinado com quádrupla felina e antirrábica, com vermifugação em dia, alimentado com ração seca, sem acesso à rua e sem contactantes. Ainda, o tutor relatou que o gato sempre ingeriu muita água e que o adotou com cerca de trinta dias de vida.

Ao exame clínico físico geral, foi observado discreta desidratação e alterações oftalmológicas no olho esquerdo com midríase, sendo possível visualização da retina descolada atrás da lente. Os demais parâmetros encontravam-se dentro do padrão fisiológico para a espécie. A partir do observado, foi solicitado a realização de exames laboratoriais, como hemograma, bioquímico e urinálise e exame de imagem, como a ultrassonografia.

\section{Resultados}

No hemograma, foi constatado linfopenia e monocitose, já no bioquímico foi observado azotemia moderada e na urinálise, proteinúria de três cruzes. O exame ultrassonográfico revelou fluido subcapsular anecogênico em ambos os rins, com baixa celularidade sendo delimitado por uma superfície capsular hiperecogênica, além de dimensões aumentadas, aumento de ecogenicidade junto de afilamento da camada cortical, contornos irregulares e perda da arquitetura habitual (Figuras 1e 2).

Durante o exame procedeu-se a drenagem do líquido, em que foi retirado cerca de $1 \mathrm{ml}$ do conteúdo transudato, revelando um líquido viscoso e límpido.

O tutor optou por não prosseguir com a drenagem, bem como não aderir ao tratamento proposto, alegando discordar da necessidade de tais medidas. O paciente foi a óbito 7 dias após a consulta. 


\section{Discussão}

A incidência de doenças renais na clínica de animais de companhia é relativamente alta, sobretudo em animais idosos (Mamprim \& Silva, 2012), e de demasia importância visto que o sistema renal é responsável pela atividade reguladora em que mantem o organismo estável em relação as diversas funções celulares, como o equilíbrio entre a produção metabólica de água eletrólitos e a eliminação dessas substâncias (

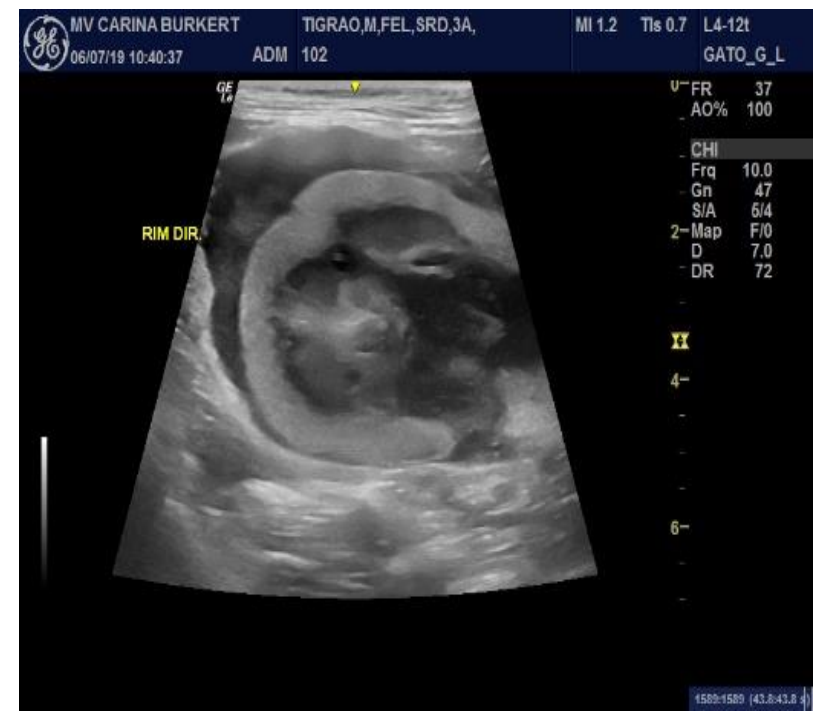

Figura 1. Imagem ultrassonográfica do rim direito do paciente evidenciando fluido subcapsular, corticais afiladas e hiperecogênicas, com perda da arquitetura renal habitual.

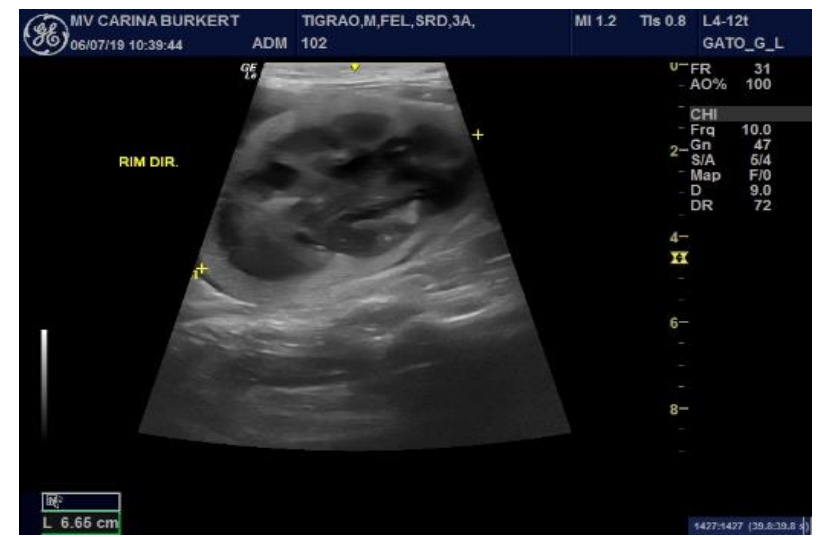

Figura 2. Imagem ultrassonográfica do rim direito do paciente evidenciando dimensões aumentadas com contorno irregular, corticais afiladas e hiperecogênicas com perda da arquitetura renal habitual.

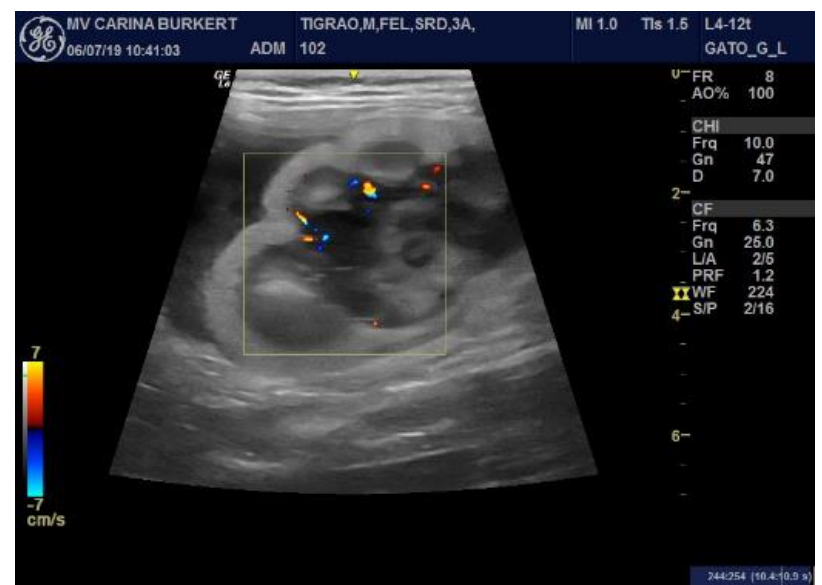

Figura 3. Imagem ultrassonográfica do rim direito do paciente evidenciando baixo fluxo sanguíneo ao modo Color Doppler. 
O pseudocisto perinéfrico é considerado entre os animais domésticos de ocorrência incomum na espécie felina (Luís et al., 2003). Caracterizado pelo acúmulo de uma grande quantidade de fluido entre o parênquima renal e sua cápsula, ao redor de um ou ambos os rins, com localização subcapsular ou extracapsular (McCord et al., 2008), bem como apresentado no presente relato a presença em de pseudocisto perinéfrico no rim direito e esquerdo, sem que haja proteção do cisto por camada epitelial (Beck et al., 2000).

Quanto a prevalência dessa enfermidade, diferentes estudos como realizados por Beck et al. (2000) e McCord et al. (2008) afirmam que felinos machos de idade mais avançada, em torno de 8 anos, que apresentam distensão abdominal e diminuição da função renal. No atual relato, o paciente tinha apenas 3 anos, apresentando precoce diminuição da função renal, pórém sem distenão abdominal notável.

$\mathrm{O}$ mecanismo fisiopatológico da doença ainda não é totalmente elucidado devido à natureza do liquido observado no cisto renal capsular não ser constante (Luís et al., 2003), sendo o transudato encontrado na maioria dos casos, em que apresenta baixo conteúdo proteico, densidade baixa e baixa celularidade (Norsworthy et al., 2004), assim como encontrado no paciente em questão. Bem como afirmado por Scherk (2008) foi observado achados condizentes com perda da função renal e o seu comprometimento, como azotemia, apresentando creatinina e ureia elevados, e proteinúria acentuada. O paciente apresentou também linfopenia e monocitose, indicando possível imunossupressão.

Seu diagnóstico é baseado em exames de imagem, principalmente na ultrassonografia, a qual quando comparado com outras modalidades de diagnóstico por imagem, como a tomografia computadorizada e a ressonância magnética, destaca-se por ser uma técnica mais acessível, mais barata, não necessitar de anestesia geral e produzir resultado em tempo real (Kealy et al., 2012), permitindo realizar a determinação das distribuições das lesões dentro do rim, diferenciar as estruturas sólidas e estruturas preenchidas por líquido, sendo útil na detecção de lesões tumorais mais precocemente, mesmo em pacientes assintomáticos (Dibartola, 1997). Os principais achados ultrassonográficos em felinos com PPR é a presença de líquido subcapsular, alterações do parênquima renal que tendem a associar-se com a nefrite intersticial, contorno irregular da cortical e a demarcação entre medular e cortical (Souza, 2016), bem como exibido neste relato.

A aspiração do fluido pode ser guiada pelo ultrassom, sendo importante para a correta avaliação da etiologia. Tendo em vista os achados de imagem e clínicos desse caso, os quais foram compatíveis com a suspeita (Halasc, 2004), fez-se o diagnóstico definitivo de pseudocisto perinéfrico.

\section{Conclusão}

Com o exposto, foi relatado de um felino, macho, sem raça definida, com aproximadamente 3 anos de idade, submetido à exame ultrassonográfico tendo como diagnostico de pseudocistos perinéfricos, visando ressaltar a importância de tal exame como método de diagnóstico para enfermidade.

\section{Referências bibliográficas}

Beck, J. A., Bellenger, C. R., Lamb, W. A., Churcher, R. K., Hunt, G. B., Nicoll, R. G., \& Malik, R. (2000). Perirenal pseudocysts in 26 cats. Australian Veterinary Journal, 78(3), 166-171. DOI: https://doi.org/10.1111/j.1751-0813.2000.tb10585.x

Dibartola, S. P. (1997). Abordagem clínica e avaliação laboratorial da afecção renal. In S. J. Ettinger \& E. C. Felddman (Eds.), Tratado de medicina interna veterinária. São Paulo: Manole (pp. 23552373).

Ferreira, A. R. A. (2008). Pseudocisto perirenal bilateral em um gato doméstico de pêlo curto: Revisão de literatura e Relato de caso. Universidade Federal da Bahia.

Halasc, V. M. (2004). Sistema urinário: rins, ureteres, bexiga urinária e uretra. In C. F. Carvalho (Ed.), Ultra-sonografia em pequenos animais (pp. 111-146). Roca.

Kealy, J. K., McAllister, H., \& Graham, J. P. (2012). Radiologia e Ultrassonografia do Cão e do Gato (Vol. 1). Manole.

Luís, J. P. S., Vieira, C., Carvalho, A. P., \& Melo, M. (2003). Pseudoquisto renal subcapsular a propósito de dois casos clínicos em gato. Revista Portuguesa de Ciências Veterinárias, 98(548), 211-216. 
Mamprim, L. C. V., \& Silva, M. J. V. C. (2012). Ultra-sonografia no diagnóstico das doenças renais em pequenos animais. Veterinária e Zootecnia, 15(3), 435-444.

McCord, K., Steyn, P. F., \& Lunn, K. F. (2008). Unilateral improvement in glomerular filtration rate after permanent drainage of a perinephric pseudocyst in a cat. Journal of Feline Medicine and Surgery, 10(3), 280-283. https://doi.org/10.1016/j.jfms.2007.11.002

Norsworthy, G. D., Crystal, M. A., Grace, S. F., \& Tilley, L. P. (2004). O paciente felino. São Paulo: Roca, 3, 300.

Raffan, E., Kipar, A., Barber, P. J., \& Freeman, A. I. (2008). Transitional cell carcinoma forming a perirenal cyst in a cat. Journal of Small Animal Practice, 49(3), 144-147. https://doi.org/10.1111/j.1748-5827.2007.00422.x

Scherk, M. (2008). Urinary tract disorders: The upper urinary tract. In S. E. Little (Ed.), The cat: clinical medicine and management (pp. 935-980). Elsevier Saunders.

Souza, M. W. P. de. (2016). Achados ultrassonográficos do rim de cães e gatos. Universidade de Brasília.

Recebido: 14 de abril, 2020.

Aprovado: 18 de maio, 2020.

Disponível online: 28 julho, 2020.

Licenciamento: Este artigo é publicado na modalidade Acesso Aberto sob a licença Creative Commons Atribuição 4.0 (CC-BY 4.0), a qual permite uso irrestrito, distribuição, reprodução em qualquer meio, desde que o autor e a fonte sejam devidamente creditados 